\title{
Experimental Evaluation of a Gas Engine Driven Heat Pump Incorporated with Heat Recovery Subsystems for Water Heating Applications
}

\author{
E. Elgendy ${ }^{1, *}$, G. Boye ${ }^{1}$, J. Schmidt ${ }^{1}$, A. Khalil ${ }^{2}$, M. Fatouh ${ }^{3}$ \\ ${ }^{1}$ Institute of Fluid Dynamics and Thermodynamics, Faculty of Process and System Engineering, \\ Otto-von-Guericke University, Universitätsplatz 2 D-39106 Magdeburg, Germany \\ ${ }^{2}$ Mechanical Power Engineering Department, Faculty of Engineering, \\ Cairo University, Giza 12316, Egypt \\ ${ }^{3}$ Mechanical Power Engineering Department, Faculty of Engineering at El-Mattaria, \\ Helwan University, Masaken El-Helmia P.O., Cairo 11718, Egypt \\ *Corresponding author. Tel: +493916712558, Fax: +493916712762, E-mail: essam.elgendy@st.ovgu.de
}

\begin{abstract}
Engine waste heat recovery represents one of the main advantages of a gas engine heat pump (GEHP) as compared to conventional heat pump system. Engine waste heat can be recovered to heat the supply water (at high ambient air temperature) or to evaporate the refrigerant in the refrigerant circuit (at low air ambient temperature). At the middle range of ambient air temperature $\left(10: 15^{\circ} \mathrm{C}\right)$, the two possibilities are valid but the GEHP performance is different. The present work is aimed at comparing the performance characteristics of the gas engine heat pump with waste heat recovery subsystems for supplying the hot water demands. In order to achieve this objective, a test facility was developed and then experiments were performed over a wide range of condenser water inlet temperature $\left(34^{\circ} \mathrm{C}\right.$ to $\left.48^{\circ} \mathrm{C}\right)$ and at ambient temperature of $13^{\circ} \mathrm{C}$. Performance of the gas engine heat pump was characterized by the supply water outlet temperature, heating capacity, gas engine energy consumption and primary energy ratio. The results showed that a water outlet temperature up to $70^{\circ} \mathrm{C}$ is obtained when the recovered engine heat is transferred to the supply water circuit. On the contrary, a higher condenser heating capacity $(13 \%)$ and higher gas engine energy consumption $(12.8 \%)$ are obtained when the recovered engine heat is transferred to the refrigerant circuit. Furthermore, primary energy ratio of the gas engine heat pump is increased by $17.5 \%$ when recovered engine heat is transferred to the supply water circuit. Also, GEHP incorporated with heat recovery subsystems can be used for utilizing the waste heat to provide efficient supply of hot water.
\end{abstract}

Keywords: Gas engine heat pump, Heating mode, Water heating, Primary energy ratio, Engine waste heat recovery.

\section{Introduction}

In Europe, more than $50 \%$ of the total final energy consumption depends on fossil fuel [1]. However, environmental pollution problems increase with consumption of fossil fuels. In order to solve these problems, a development for alternative energy sources and improvement of energy utilization efficiency are required. Heat pumps (HPs) play an important role in solving energy and environment problems as they can improve the overall energy utilization efficiency and can work with environmentally friendly refrigerants [2-4].

Heat pumps can be divided into many categories according to energy sources, namely electric driven heat pumps (EHPs), ground-source heat pumps (GSHPs), solar-assisted heat pumps and gas engine driven heat pumps (GEHPs). A GEHP usually consists of a reversible vapor compression heat pump with an open compressor driven by an engine. In recent years, the GEHP has been paid more attention due to its advantage of reducing the energy consumption, especially in the heating process. Another two advantages of the GEHP are (1) the ability to recover the waste heat released by the engine cylinder jacket and exhaust gas and (2) the easy modulation of compressor speed by adjusting the gas supply. Therefore, the GEHP has a better performance than that of the electric driven heat pump (EHP), especially in the heating mode [5]. 
Performance characteristics of the GEHP during heating mode were evaluated by many investigators using theoretical modeling [5-7] and experimental approach [8]. Regarding to theoretical modeling of the GEHP, Zhang et al. [5] analyzed the effect of both ambient temperature and engine speed on the heating performance of air to water GEHP based on steady state model. Their results proved that the engine speed had a remarkable effect on both the engine and the heat pump, but ambient air temperature had a little influence on the engine performance. Yang et al. [6] reported an intelligent control simulation model for the GEHP system in heating mode to study the dynamic characteristics of the system. The results showed that the model was very effective in analyzing the effects of the control system. The steady state accuracy of the intelligent control scheme was higher than that of the fuzzy controller. Sanaye and Chahartaghi [7] predicted the performance of the GEHP under cooling and heating operating modes and then compared the simulation and experimental results for various amounts of suction and discharge pressures, fuel consumption and coefficient of performance. They noted that error percentages of suction and discharge pressures, fuel consumption and coefficient of performance are $3.4 \%, 4 \%, 6.7 \%$ and $7.2 \%$ for cooling mode, respectively, and $3.7 \%, 5.4 \%, 8.1 \%$ and $7.8 \%$ for heating mode, respectively.

Regarding to the experimental studies of the GEHP, Lazzarin and Noro [8] evaluated the performance of 'S. Nicola' plant in Vicenza during three years of operation. Plant heating loads are supplied using the GEHP and two condensing boilers. Recovered engine heat is used in water heating. The economic analysis was taken into account while the energy efficiencies were not taken into considerations.

The above review revealed that various investigations on m odeling of the GEHPs are available in the literature while there is a lack of experimental data on the GEHPs working with R22 alternatives such as R410A. Thus, the present work is carried out with the aim of evaluating the performance characteristics of the GEHP used in water heating incorporated with different heat recovery sub-systems. In order to achieve this aim, a test facility of the GEHP is constructed and equipped with the necessary instrumentation. This paper is organized as follows. The experimental apparatus to predict the performance of characteristics of the GEHP is described in Section 2 while the data reduction manipulation is given in Section 3. This is followed by the experimental results and discussion in Section 4. Finally, conclusions based on the present work results are reported in Section 6.

\section{Experimental apparatus}

Fig. 1 shows a s chematic diagram of the experimental apparatus, which includes three circuits; namely primary working fluid circuit, engine coolant circuit and secondary working fluid circuit. R410A is used as a primary working fluid while both air and water are used as secondary heat transfer fluids at the heat source (evaporator) and the heat sink (condenser). In the engine coolant circuit, both ethylene-water mixture ( $65 \%$ by volume) and propylene-water mixture ( $45 \%$ by volume) are used as cooling mediums. Pre-calibrated PT100 sensors are used to measure operating temperatures while digital pressure gauges are used to determine the operating pressures at four locations in the refrigerant circuit of the heat pump. The mass flow rate of refrigerant is measured using KROHNE Optimass 7000-T10 while engine coolant and water flow rates are measured using Ultego-II flow sensors. The measurement locations are shown in Fig. 1. All the measuring instruments have been installed and connected to 64 channels in the data acquisition cards (FP-1000). The control system has been established using PRIVA software which provides several possibilities for indoor unit selection and consequently system operation. All the measured data are recorded using DIAdem software and analyzed using an EES program [9] to evaluate the system performance. Performance 
characteristics of the system in both cooling, heating and combined modes were published by Elgendy et al. [10-12].

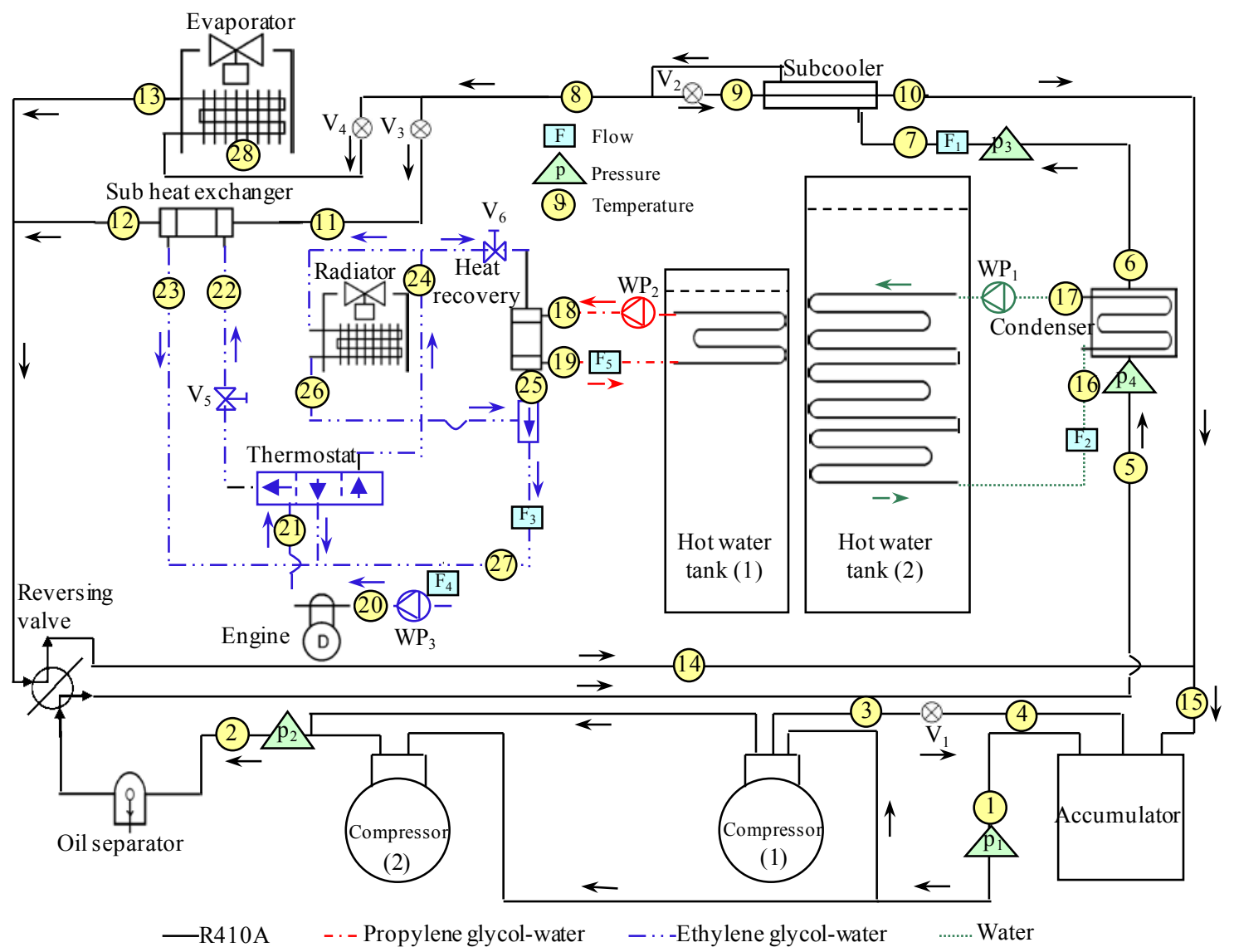

Fig. 1. Schematic diagram of the experimental apparatus with measuring point locations.

\subsection{Primary working fluid circuit}

The primary working fluid circuit is a vapor compression heat pump. It comprises an expansion device, an evaporator, an open compressor and a condenser followed by a subcooler. The expansion device is an electronic expansion valve whereas the compressor is a scroll open type with swept volume of $104 \mathrm{~cm}^{3} / \mathrm{rev}$. The type of condenser is a plate heat exchanger with a heat transfer area of $4.6 \mathrm{~m}^{2}$. Two pressure-stats, one on the suction side and the other on the discharged side, are used to protect the compressor from under and over operating pressures. If the pressure exceeds its limits, the compressor would be automatically disconnected. In order to reduce the heat transfer to and from the surroundings, the primary fluid circuit is thermally insulated.

As the refrigerant flows to the compressors (state point 1), the compressors raise the pressure of the refrigerant and deliver superheated vapor (state point 2) to the condenser (state point 5) through an oil separator and a reversing valve. The condensation heat of refrigerant vapor is released to the water flowing through the condenser. Thus, R410A vapor gets condensed (state point 6) and its mass flow rate is measured using flow-meter $F_{1}$ before it flows to the sub-cooler. The liquid refrigerant in the sub-cooler is sub-cooled (state point 8) by transfer its heat to the throttled refrigerant flowing through valve $\mathrm{V}_{2}$. Then, the refrigerant is throttled using expansion devices $\mathrm{V}_{3}$ and $\mathrm{V}_{4}$ and evaporated inside either the evaporator or the sub heat exchanger using the heat transferred from either ambient air or the recovered heat from the engine, respectively. Superheated refrigerant coming out of sub-cooler (state point 10), 
sub heat exchanger (state point 12) and outdoor unit (state point 13) are mixed (state point 15) before entering the accumulator and then returning back to the compressors (state point 1).

\subsection{Secondary fluid circuit}

The experimental apparatus has two secondary heat transfer fluid circuits; namely hot water circuit and outdoor air circuit. The hot water circuit contains a hot water tank of $1 \mathrm{~m}^{3}$ capacity, a hot water pump, a condenser and control valves. The water pump (single phase, variable speed) is used to suck and pump the hot water through the condenser and hot water pipeline. The hot water flow rate is adjusted via pump speed. The hot water circuit is thermally insulated to minimize heat loss. The outdoor air circuit consists of an air filter, a fan and an evaporator. The hot water coming out of the condenser (state point 17) is pumped to a storage tank (1) using variable speed water pump $W_{1}$. Storage tank (1) is used for hot water coming from the engine heat recovery while storage tank (2) is used for the hot water coming out of the condenser. The volume flow rates of hot waters are measured using ultrasonic flow meters $\mathrm{F}_{2}$ and $\mathrm{F}_{5}$, respectively.

\subsection{Engine coolant circuit}

The engine coolant circuit includes a gas engine, a coolant tank, a coolant pump, valves and coolant pipeline. Coolant discharged from the coolant pump (state point 20) is heated by the heat released from the engine block and exhaust gas (state point 21). The heated coolant returns to the coolant pump by making a shortcut via a thermostat valve when the coolant temperature is low (lower than $53^{\circ} \mathrm{C}$ ) at engine start-up. When the coolant temperature is high (higher than $53^{\circ} \mathrm{C}$ ) the coolant flows into sub heat exchanger while it flows through all of sub heat exchanger, radiator and heat recovery heat exchangers when the coolant temperature is very high (higher than $67^{\circ} \mathrm{C}$ ). The outlet coolant from both heat recovery heat exchanger (state point 25) and radiator (state point 26) is mixed (state point 27) and its volume flow rate is measured using ultrasonic flow meter $\left(\mathrm{F}_{3}\right)$ before returning back to the coolant pump. Heat gained in the heat recovery heat exchanger is supplied to the water in the tank (1) using propylene-water mixture as a working medium (state points 18 and 19). According to engine heat recovered utilization (from the engine block and exhaust gas), the system can be worked in two sub modes:

Mode-I: in which the recovered engine heat is transferred to the secondary water circuit in order to reach higher hot water supply (using the heat recovery heat exchanger). So, valves $V_{3}$ and $\mathrm{V}_{5}$ are closed while $\mathrm{V}_{6}$ is open.

Mode-II: in which the recovered engine heat is transferred to the primary refrigerant circuit to evaporate the working fluid, especially at low ambient air temperature (using the sub heat exchanger). Hence, valves $V_{3}$ and $V_{5}$ are open while $V_{6}$ is closed.

\section{Data reduction}

Using the measured data of operating pressures and temperatures of R410A, ethylene glycolwater mixture, propylene glycol-water mixture and water, the specific enthalpy values at the inlet and outlet of each component $\left(\mathrm{h}_{1} \rightarrow \mathrm{h}_{27}\right)$ are estimated. Then, energy and mass balances are carried out for the main components of the gas engine heat pump to compute their loads in addition to the overall system performance. Condenser heat load $\left(\dot{\mathrm{Q}}_{\mathrm{con}}\right)$ can be written based on either primary working fluid (Eq. 1.a) or secondary working fluid (Eq. 1.b) as follows;

$\dot{\mathrm{Q}}_{\text {con }}=\dot{\mathrm{M}}_{\text {ref,p }}\left(\mathrm{h}_{5}-\mathrm{h}_{6}\right)$ 
$\dot{\mathrm{Q}}_{\text {con }}=\dot{\mathrm{V}}_{\text {con, } \mathrm{w}} \rho_{\mathrm{w}}\left(\mathrm{h}_{17}-\mathrm{h}_{16}\right)$

Applying energy balance around sub-cooler, the secondary refrigerant mass flow rate $\left(\dot{M}_{\text {ref,s }}\right)$ flowing through sub-cooler can be calculated as follows;

$\dot{\mathrm{M}}_{\mathrm{ref}, \mathrm{s}}=\frac{\dot{\mathrm{Q}}_{\mathrm{sub}}}{\left(\mathrm{h}_{10}-\mathrm{h}_{9}\right)}$

where,

$\dot{\mathrm{Q}}_{\text {sub }}=\dot{\mathrm{M}}_{\mathrm{ref}, \mathrm{p}}\left(\mathrm{h}_{7}-\mathrm{h}_{8}\right)$

$\dot{\mathrm{M}}_{\text {ref,p }}$ is the primary refrigerant mass flow rate, which is measured using flow meter $\mathrm{F}_{1}$. Gas engine heat recovery $\left(\dot{\mathrm{Q}}_{\mathrm{HR}}\right)$ can be calculated using Eq. (3);

$\dot{\mathrm{Q}}_{\mathrm{HR}}=\dot{\mathrm{V}}_{\mathrm{hw}} \rho_{\mathrm{w}}\left(\mathrm{h}_{19}-\mathrm{h}_{18}\right)$.

Ultrasonic flow meters $\mathrm{F}_{2}$ and $\mathrm{F}_{5}$ are used to measure condenser water $\left(\dot{\mathrm{V}}_{\mathrm{con}, \mathrm{w}}\right)$ and hot water $\left(\dot{\mathrm{V}}_{\mathrm{hw}}\right)$ volume flow rates through the condenser and heat recovery heat exchanger, respectively. Primary energy ratio (PER), gas engine heat consumption $\left(\dot{\mathrm{Q}}_{\text {gas }}\right)$ and total heating capacity $\left(\dot{Q}_{\text {tot }}\right)$ are the main parameters to be considered in the performance evaluation of the GEHP [13]. PER and $\dot{\mathrm{Q}}_{\mathrm{gas}}$ can be expressed as follows;

$$
\mathrm{PER}=\frac{\dot{\mathrm{Q}}_{\mathrm{tot}}}{\dot{\mathrm{Q}}_{\mathrm{gas}}},
$$

$\dot{\mathrm{Q}}_{\mathrm{tot}}=\dot{\mathrm{Q}}_{\mathrm{con}}+\dot{\mathrm{Q}}_{\mathrm{HR}}$

$\dot{\mathrm{Q}}_{\text {gas }}=\dot{\mathrm{V}}_{\mathrm{gas}} \mathrm{LHV}$

where LHV is the gas lower heating value and $\dot{\mathrm{V}}_{\text {gas }}$ is the measured gas volume flow rate using diaphragm gas meter.

\section{Results and discussions}

Fig. 2 shows comparison of performance characteristics of the GEHP for the prescribed mode-I and mode-II and at ambient temperature of $13^{\circ} \mathrm{C}$. In mode-I, recovered engine heat is transferred to the water supply while recovered engine heat is transferred to the refrigerant in mode-II. The system hot water outlet temperature was adjusted between $35^{\circ} \mathrm{C}$ and $70^{\circ} \mathrm{C}$ to 

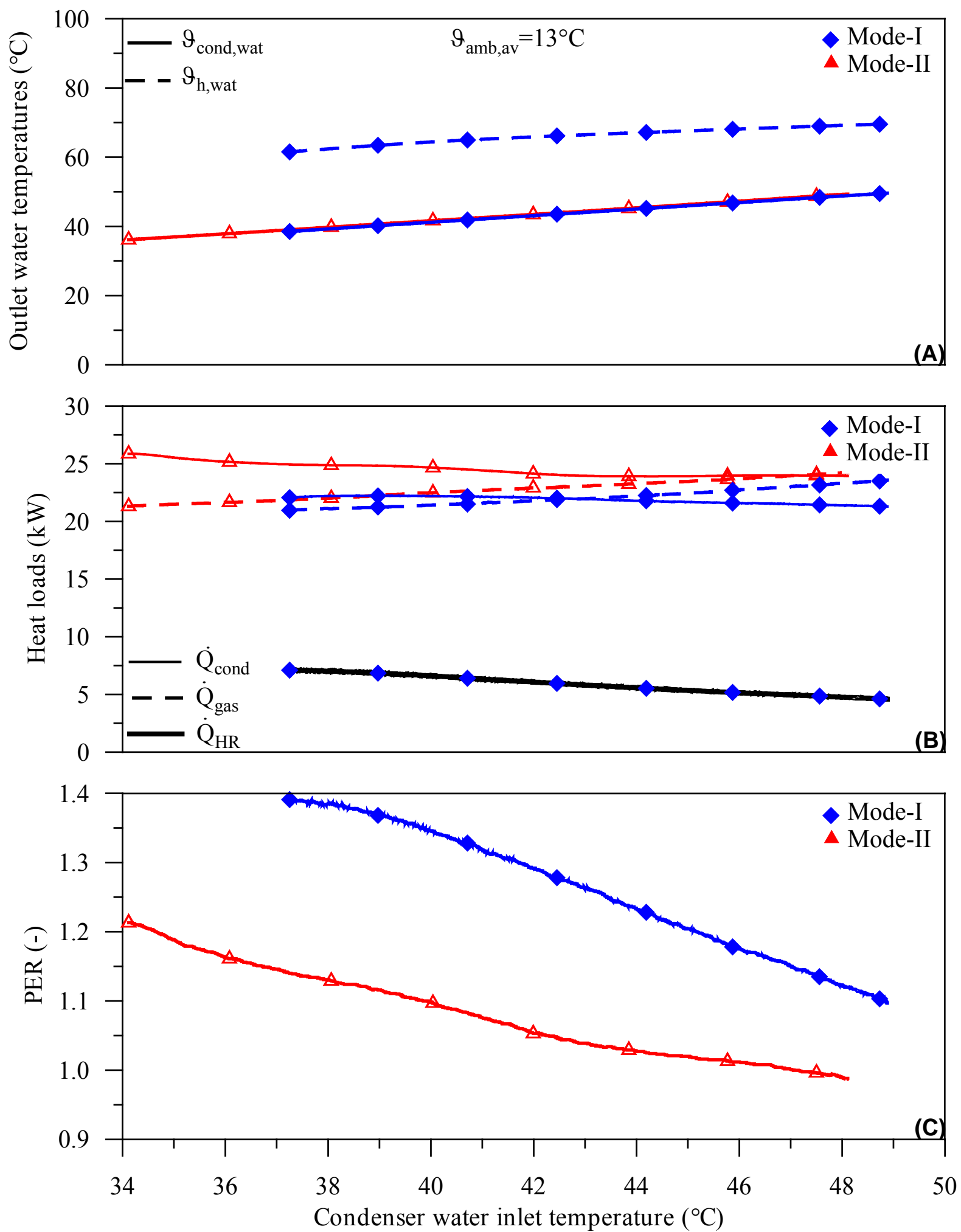

Fig. 2. Effect of condenser water inlet temperature on the performance characteristics of the GEHP for Mode-I and Mode-II. (A) outlet water temperatures, (B) heat loads and (C) PER.

provide heating requirements for several applications like shaving, residential dish washing and laundry [14]. 


\subsection{Effect of condenser water inlet temperature}

Measured condenser and heat recovery water outlet temperatures against the condenser water inlet temperature are presented in Fig. 2.A, which indicates that condenser and heat recovery water outlet temperatures increase when condenser water inlet temperature increases. Variations of actual heat loads with condenser water inlet temperature are shown in Fig. 2.B. It is evident from this figure that total heating capacity and gas engine heat recovery decrease while gas engine energy consumption $\dot{\mathrm{Q}}_{\text {gas }}$ increases as condenser water inlet temperature increases. It is observed that both of the condenser and heat recovery water temperature differences decrease causing the decrease of total heating capacity. In general, as the condenser water inlet temperature changes from $37^{\circ} \mathrm{C}$ to $48^{\circ} \mathrm{C}$, total heating capacity decreases by $8.3 \%$ and $4.7 \%$ while gas engine energy consumption increases by $14.1 \%$ and $11.9 \%$ for mode-I and mode-II, respectively. The effect of condenser water inlet temperature on PER can be predicted from Fig. 2.C. A higher condenser water inlet temperature yields a lower PER. This trend is mainly due to both decrease in total heating capacity and increase in the gas engine energy consumption as shown in Fig. 2.C. Clearly, primary energy ratio of the GEHP decreases by $27.2 \%$ and $17.3 \%$ as the condenser water inlet temperature varies from $37^{\circ} \mathrm{C}$ to $48^{\circ} \mathrm{C}$ for mode-I and mode-II, respectively.

\subsection{Comparison between mode-I and mode-II}

Comparison of the measured condenser and heat recovery water outlet temperatures for mode-I and mode-II are presented in Fig. 2.A. In the two modes, the condenser water outlet temperature lies between $35^{\circ} \mathrm{C}$ and $50^{\circ} \mathrm{C}$. For mode-I, a higher hot water temperature (up to $70^{\circ} \mathrm{C}$ ) can be achieved as a result of recovered engine heat transfer. Variations of actual heat loads for the modes are shown in Fig. 2.B. It is evident from this figure that condenser heating capacity and gas engine energy consumption are high when recovered engine heat is transferred to refrigerant. In general, both condenser heating capacity and gas engine energy consumption increase by $13 \%$ and $12.4 \%$ as an average values, respectively. So, it is better to transfer recovered engine heat to the refrigerant when one needs a large amount of heat at lower range of temperature $\left(35^{\circ} \mathrm{C}: 50^{\circ} \mathrm{C}\right)$ while it is better to transfer engine heat to water when a higher water temperature (up to $70^{\circ} \mathrm{C}$ ) is required. The effect of the condenser water inlet temperature on the PER for the two modes can be predicted from Fig. 2.C. A higher PER can be reached when the recovered engine heat is transferred to the water. This can be attributed mainly to the higher gas engine heat recovery. Clearly, primary energy ratio of the GEHP increases by $17.5 \%$ as an average value over the entire range of the condenser water inlet temperature (from $37.2^{\circ} \mathrm{C}$ to $48^{\circ} \mathrm{C}$ ).

\section{Conclusion}

In the present work, performance characteristics of R410A gas engine heat pump have been experimentally compared under two different modes of heat recovery utilization. In mode-I, recovered engine heat is transferred to the water supply while recovered engine heat is transferred to the refrigerant in mode-II. Based on the reported results, the following conclusions are drawn:

- Hot water outlet temperatures between $35^{\circ} \mathrm{C}$ and $50^{\circ} \mathrm{C}$ are obtained during the considered modes.

- Water outlet temperatures up to $70^{\circ} \mathrm{C}$ can be reached in a separate tank when recovered engine heat is transferred to water. 
- As the condenser water inlet temperature varies from $37^{\circ} \mathrm{C}$ to $48^{\circ} \mathrm{C}$, total heating capacity decreases by $8.3 \%$ and $4.7 \%$ while gas engine energy consumption increases by $14.1 \%$ and $11.9 \%$ for mode-I and mode-II, respectively.

- Primary energy ratio of the GEHP increases by $17.5 \%$, when recovered engine heat is transferred to water.

\section{Acknowledgment}

The Authors are grateful for the installation of the testing plant and the financial support provided by Wärmetechnik Quedlinburg (WTQ) GmbH. The financial support of the Egyptian government for the Ph.D. of Mr. Elgendy is gratefully acknowledged.

\section{References}

[1] H. Laue, Heat Pumps, Heinloth K. Renewable Energy, Germany, Springer Berlin Heidelberg, 2006.

[2] J. P. Meyer, G. P. Greyvenstein, Hot water for homes in South Africa with heat pumps, Energy 1991, 16(7), pp.1039-44.

[3] G. P. Greyvenstein, J. P. Meyer, The viability of heat pumps for the heating of swimming pools in South Africa, Energy 1991, 16(7), pp.1031-1037.

[4] S. Garimella, Innovations in energy efficient and environmentally friendly spaceconditioning systems, Energy 2003, 28(15), pp.1593-1614.

[5] R. R. Zhang, X. S. Lu, S. Z. Li, W. S. Lin, A. Z. Gu, Analysis on the heating performance of a gas engine driven air to water heat pump based on a steady state model, Energy Conversion and Management 2005, 46, pp.1714-1730.

[6] Z. Yang, Z. Haibo, F. Zheng, Modeling and dynamic control simulation of unitary gas engine heat pump, Energy Conversion and Management 2007, 48(12), pp.3146-3153.

[7] S. Sanaye, M. Chahartaghi, Thermal modelling and operating tests for the gas enginedriven heat pump systems, Energy 2010, 35(1), pp.351-363.

[8] R. Lazzarin, M. Noro, District heating and gas engine heat pump: economic analysis based on a case study, Applied Thermal Engineering 2006, 26, pp.193-199.

[9] S. A. Klein, EES-Engineering Equation Solver, Professional Version, Middleton, WI, FChart Software, 2009.

[10]E. Elgendy, J. Schmidt, Experimental study of gas engine driven air to water heat pump in cooling mode, Energy 2010, 35(4), pp.2461-2467.

[11]E. Elgendy, J. Schmidt, A. Khalil, M. Fatouh, Performance of a Gas Engine Driven Heat Pump for Hot Water Supply Systems, Energy 2011, In press.

[12]E. Elgendy, J. Schmidt, A. Khalil, M. Fatouh, Performance of a Gas Engine Heat Pump using R410A for Heating and Cooling Applications, Energy 2010, 35(12), pp.4941-4948.

[13]K. Taira, Development of a 2.5-RT multiple-indoor-unit gas engine heat pump, ASHRAE Trans 1998, 24, pp.982-988.

[14]ASHRAE, ASHRAE handbook, application, Atlanta, American Society of Heating Refrigerating and Air-conditioning Engineers, 2007. 